\title{
PENSION SECURITY FOR CITIZENS OF THE RUSSIAN FEDERATION: SOCIAL RISKS
}

\author{
Natalya P. Pazdnikova \\ Perm National Research Polytechnic University, Perm, Russian Federation; \\ Perm State National Research University, Perm, Russian Federation \\ Alena Yu. Vazhenina \\ Perm State National Research University, Perm, Russian Federation
}

\begin{abstract}
The formation of a pension system that has integrity, safety, efficiency and meets the needs of citizens is a socially significant and scientific task. To solve such problems, it is necessary not only to focus on the priorities of strategic planning, but also to constantly search for methodological tools, new regulatory levers and management methods, especially in the face of increasing all kinds of social risks. The purpose of the study is to show the need to address issues related to the identification of social risks, assessment of their impact on the citizens' pension provision, which will ensure a clear understanding of the effectiveness of the applied mechanisms of state pension insurance in the Russian Federation. The author's research was carried out on the basis of statistical, regulatory, expert, balance methods, as well as the stress testing method, which made it possible to assess the level of social risks of one of the constituent entities of the Russian Federation. The main results of the study are as follows: the current statistics of the state of pension provision of Russian citizens is presented; a method of stress testing for identification and assessment of the level of social risks was proposed and tested; the key factors of the emergence of the latter are identified. The article reflects scientific results that demonstrate the normal level of social risks and the adequacy of reserves in the event of their strengthening on the example of a specific subject. The main conclusions of the authors prove the need for social risk management and the formation of an effective pension system for Russian citizens, taking the implementation of preventive measures into account. Reducing social risks for the population will make it possible to successfully pursue state policy and have civil confidence in the future.
\end{abstract}

Key words: pension system, pension provision, social risk, risk identification, expenditure on pensions.

Citation. Pazdnikova N.P., Vazhenina A.Yu. Pension Security for Citizens of the Russian Federation: Social Risks. Vestnik Volgogradskogo gosudarstvennogo universiteta. Ekonomika [Journal of Volgograd State University. Economics], 2021, vol. 23, no. 2, pp. 122-129. (in Russian). DOI: https://doi.org/10.15688/ek.jvolsu.2021.2.10

\section{ПЕНСИОННОЕ ОБЕСПЕЧЕНИЕ ГРАЖДАН РОССИЙСКОЙ ФЕДЕРАЦИИ: СОЦИАЛЬНЫЕ РИСКИ}

\section{Наталья Павловна Паздникова}

Пермский национальный исследовательский политехнический университет, г. Пермь, Российская Федерация; Пермский государственный национальный исследовательский университет, г. Пермь, Российская Федерация

\section{Алена Юрьевна Важенина}

Пермский государственный национальный исследовательский университет, г. Пермь, Российская Федерация

Аннотация. Формирование системы пенсионного обеспечения, обладающей целостностью, безопасностью, эффективностью и удовлетворяющей потребности граждан, является общественно значимой и на- 
учной задачей. Для ее решения необходимо не только ориентироваться на приоритеты стратегического планирования, но и осуществлять постоянный поиск методических инструментов, новых рычагов регулирования и способов управления, особенно в условиях возрастания всевозможных социальных рисков. Цель исследования - показать необходимость решения вопросов, связанных с идентификацией социальных рисков, оценкой их воздействия на пенсионное обеспечение граждан, что позволит дать четкое понимание эффективности применяемых механизмов государственного пенсионного страхования в Российской Федерации. На основе статистического, нормативного, экспертного, балансового методов, а также метода стресстестирования проводилось авторское исследование, что позволило оценить уровень социальных рисков одного из субъектов Российской Федерации. Основные полученные результаты исследования таковы: представлена актуальная статистика состояния пенсионного обеспечения российских граждан; предложен и апробирован метод стресс-тестирования к идентификации и оценке уровня социальных рисков; выделены ключевые факторы возникновения последних. В статье отражаются научные результаты, которые демонстрируют нормальный уровень социальных рисков и достаточность резервов в случае их усиления на примере конкретного субъекта. Основные выводы авторов доказывают необходимость управления социальными рисками и формирование эффективной системы пенсионного обеспечения российских граждан с учетом проведения предупреждающих мер. Снижение социальных рисков для населения позволит успешно проводить государственную политику и иметь гражданское доверие в будущем.

Ключевые слова: пенсионная система, пенсионное обеспечение, социальный риск, идентификация риска, расходы на выплату пенсий.

Цитирование. Паздникова Н. П., Важенина А. Ю. Пенсионное обеспечение граждан Российской Федерации: социальные риски // Вестник Волгоградского государственного университета. Экономика. - 2021. T. 23, № 2. - C. 122-129. - DOI: https://doi.org/10.15688/ek.jvolsu.2021.2.10

\section{Введение}

Актуальность исследования результатов реструктуризации пенсионной системы в конечном итоге затрагивает каждого российского гражданина. В Российской Федерации в основе построения пенсионной системы лежат страховые принципы и те риски, которые связаны с жизнедеятельностью человека, служат предпосылкой возникновения страховых отношений. В экономике, которая основана на социализации, социальные риски имеют особое значение, поскольку являются наиболее масштабными и значимыми для развития общества и государства. Об этом свидетельствует актуализация такого рода рисков при рассмотрении вопросов социальной защиты в основных государственных нормативно-правовых документах [Дмитриев, 2013].

Понятие социального риска в рамках экономических процессов зачастую трактуется как вероятность наступления материальной необеспеченности, недофинансирования социальной обеспеченности по причине изменения трудового договора, а также возникновения потребности в дополнительных расходах на лечение и социальные услуги. В классификацию социальных рисков входят пенсионные. Однако в отечественных научных публикациях до сих пор не существует общепринятого понятия «пенсионный риск». В теории под ним понимается изменение трудового дохода работника по причине утраты трудоспособности, связанной с его возрастом и невозможностью участия в трудовом процессе [Паздникова и др., 2014].

\section{Постановка проблемы по результатам исследования}

Рассматривая состояние пенсионной системы, необходимо затронуть двойственный характер происхождения процесса пенсионного обеспечения. С одной стороны, пенсионное обеспечение является механизмом экономической безопасности общества за счет предотвращения социально-значимых угроз для различных социальных групп, а с другой денежной компенсацией, которая зависит от выработанного стажа и уровня заработной платы. В настоящее время величина пенсий у большинства граждан Российской Федерации находится на достаточно низком уровне и не может сравниваться с аналогичными показателями большинства развитых стран. Предполагаемое повышение уровня пенсионного обеспечения российских граждан не было достигнуто в результате возникших проблем 
проводимой пенсионной реформы [Амелин, 2018]. Так, величина прожиточного минимума пенсионера в Пермском крае гораздо ниже величины прожиточного минимума «экономически активного» населения Российской Федерации, а средний размер страховой пенсии едва превышает минимальный размер оплаты труда [Жукова, 2015].

Как показал проведенный анализ, наибольшую часть расходов бюджета Отделения Пенсионного фонда России по Пермскому краю составляют расходы на выплату пенсий. Удельный вес расходов на выплату пенсий в период 2015-2019 гг. в среднем составляет $87 \%$. При этом существенную угрозу для устойчивости пенсионной системы территории представляет превышение числа и доли пенсионеров над трудоспособным населением (табл. 1).

При этом темпы роста численности трудоспособного населения и численности пенсионеров снижаются, что обусловлено рядом причин социально-экономического характера: снижением качества жизни населения и миграцией трудоспособного населения за пределы России. Молодежная миграция набирает темпы и, по мнению экспертов, продолжит свой рост в будущем. Интересен и тот факт, что темпы роста численности работающих пенсионеров резко снизились в 2018 г. в связи с Указами Президента о реструктуризации уровня пенсий. Однако в 2019 г. вновь темп роста численности работающих пенсионеров достиг отметки $98,1 \%$, что, вероятнее всего, связано с резким падением денежных доходов пенсионеров и необходимостью их увеличивать.

Отметим тот факт, что непропорциональное соотношение работающего трудоспо- собного населения и работающих пенсинеров в Пермском крае не отличается от общей картины в Российской Федерации (см. рис. 1).

Увеличение числа пенсионеров связано с демографическими процессами, такими как: увеличение продолжительности жизни, снижение уровня рождаемости, демографическое старение населения и др. Существенный рост числа пенсионеров в Пермском крае наблюдается в период 2015-2018 годов. В 2019 г. рост данного показателя замедлился, что связано с мерами повышения пенсионного возраста - 60 лет у женщин и 65 лет у мужчин.

В рамках проводимой политики повышения уровня пенсионного обеспечения граждан Российской Федерации в Пермском крае наблюдается ежегодное увеличение размера пенсионных выплат, однако масштабность проблем, противоречивость и слабая защищенность населения от различного рода угроз внешнего и внутреннего характера сказываются на состоянии пенсионной системы территорий в целом. Темп роста размера пенсионных выплат в Пермском крае в среднем составляет $6 \%$ (см. рис. 2).

Исходя из рисунка 2, можно наблюдать рост размеров всех видов пенсий, однако наиболее существенный рост заметен по страховой пенсии по старости в период 2015-2019 годов. Кроме того, согласно конвенции Международной организации труда «О минимальных нормах социального обеспечения», коэффициент замещения для пенсионеров, рассчитываемый от среднего размера заработной платы, должен быть не ниже 40 \% [Конвенция Международной организации труда].

Коэффициент замещения по Пермскому краю представлен в таблице 2.

Таблича 1

Численность трудоспособного населения от числа пенсионеров, тыс. чел., \%

\begin{tabular}{|c|c|c|c|c|c|}
\hline Показатель & 2015 г. & 2016 г. & 2017 г. & 2018 г. & 2019 г. \\
\hline Численность трудоспособного населения & 1304,7 & 1313,2 & 1282,1 & 1265,0 & 1225,0 \\
\hline Рост (темп) & - & 100,6 & 97,6 & 98,7 & 96,8 \\
\hline Численность пенсионеров & 793,5 & 799,3 & 803,2 & 796,1 & 794,9 \\
\hline Рост (темп) & - & 100,7 & 100,5 & 99,1 & 99,8 \\
\hline Численность работающих пенсионеров & 162,7 & 158,5 & 155,2 & 145,2 & 142,5 \\
\hline Рост (темп) & - & 97,4 & 97,9 & 93,5 & 98,1 \\
\hline Доля пенсионеров от трудоспособного населения & 60,8 & 60,9 & 62,6 & 62,9 & 64,9 \\
\hline $\begin{array}{l}\text { Доля работающих пенсионеров от трудоспособ- } \\
\text { ного населения }\end{array}$ & 12,5 & 12,1 & 12,1 & 11,5 & 11,6 \\
\hline
\end{tabular}

Примечание. Составлено авторами по [Информационно-аналитическая система Федерального ...]. 
Н.П. Паздникова, А.Ю. Важенина. Пенсионное обеспечение граждан Российской Федерации

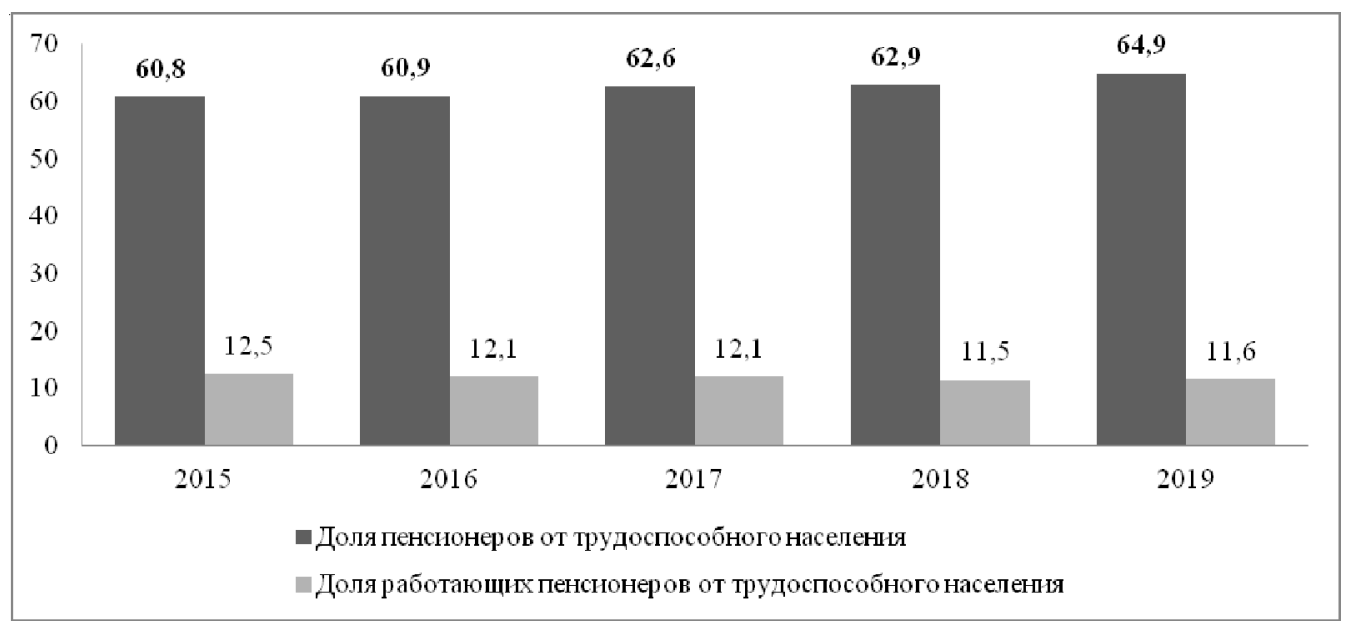

Рис. 1. Соотношение работающих и неработающих пенсионеров в Пермском крае 2015-2019 гг., \%

Примечание. Составлено по: [Информационно-аналитическая система «Пояснительные записки ...].

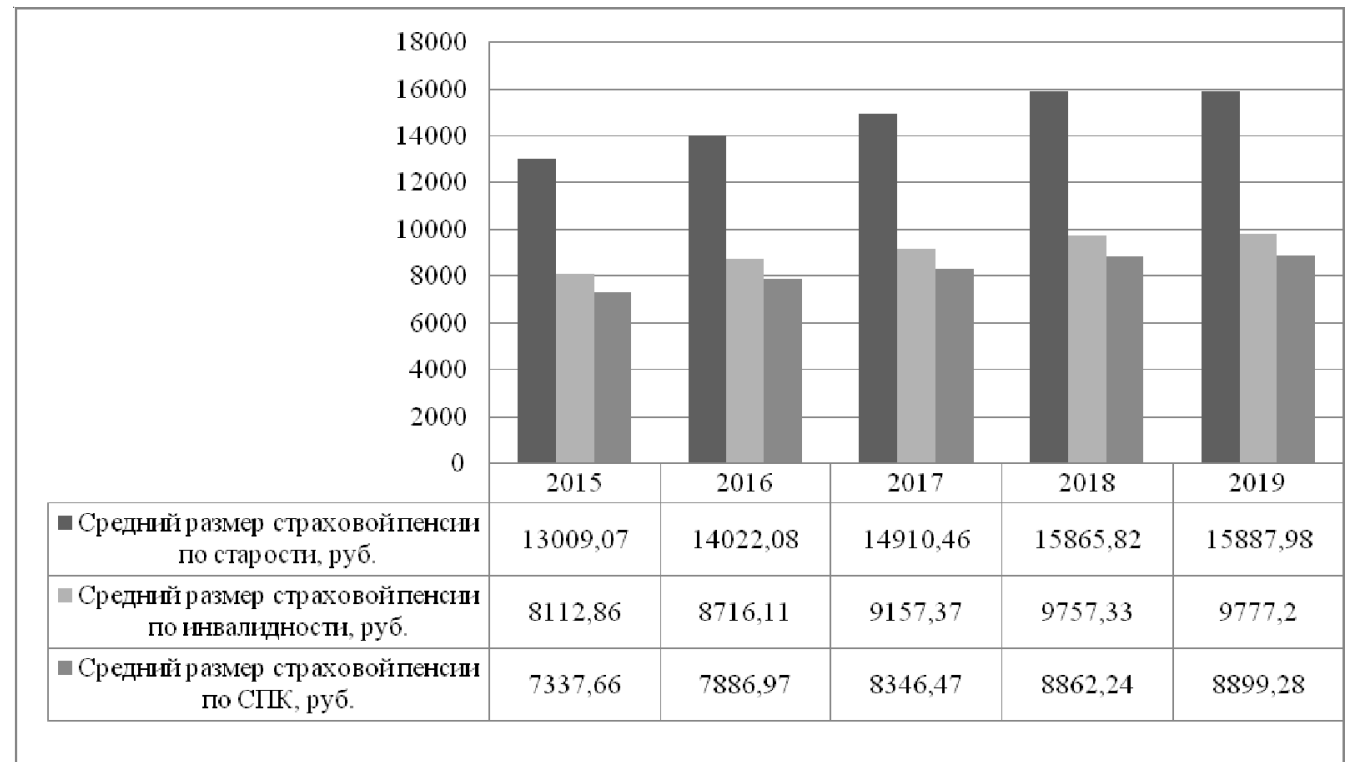

Рис. 2. Количественное соотношение размера пенсионного обеспечения Пермского края 2015-2019 гг., руб.

Примечание. Составлено авторами по: [Информационно-аналитическая система «Пояснительные записки ...].

Таблица 2

Соотношение среднего размера пенсии и заработной платы по Пермскому краю (коэффициент замещения)

\begin{tabular}{|c|c|c|c|}
\hline Годы & $\begin{array}{c}\text { Средний размер пенсий, } \\
\text { руб. }\end{array}$ & $\begin{array}{c}\text { Средний размер } \\
\text { заработной платы, руб. }\end{array}$ & Коэффициент замещения, \% \\
\hline 2015 & 11942,30 & 28527,80 & 41,9 \\
\hline 2016 & 17323,10 & 30651,20 & 56,5 \\
\hline 2017 & 13250,30 & 32951,50 & 40,2 \\
\hline 2018 & 14069,70 & 35802,10 & 39,3 \\
\hline 2019 & 14926,40 & 39802,00 & 37,5 \\
\hline
\end{tabular}

Примечание. Составлено авторами по: [Информационно-аналитическая система Федерального ...]. 
Ситуация с нормами социального обеспечения пенсионеров ухудшается в период 2018-2019 гг. в связи с несоотносимыми изменениями размеров пенсий и заработной платы российских граждан, а также рост численности пенсионеров приводит к сокращению коэффициента замещения и снижению размера пенсий соответственно. Отметим, что размер пенсий у большинства граждан Пермского края неприемлем с точки зрения обеспечения необходимого уровня жизни пенсионеров.

Проблемы пенсионного обеспечения демонстрируют еще два показателя - уровень бюджетной достаточности и уровень бюджетной обеспеченности (рис. 3).

Показатели уровня бюджетной достаточности в Пермском крае, оцениваемые относительно среднего размера пенсий, прожиточного минимума пенсионера в Пермском крае, демонстрирует уровень бюджетной обеспеченности на 1 пенсионера, который значительно превышает прожиточный минимум и средний размер пенсий пенсионеров в этом регионе. При оценке бюджетной обеспеченности самый высокий уровень отмечался в 2019 г. - 16315,40 руб. / чел. При этом с 2015 г. показатель имеет тенденцию роста, однако нехватка собственных средств Отделения пенсионных фондов по Пермскому краю не повлияла на полную и своевременную выплату пенсий, так как была поддержка федерального бюджета [Атанесян, 2020].

\section{Вероятностная оценка социального риска}

Безусловно, выявленные проблемы в ходе анализа детерминируют возможные социальные риски, которые нужно идентифицировать, оценивать и минимизировать [Кубарь, 2016]. Ряд специфических особенностей территории влияет на степень социальных рисков, которые, как и любые другие виды риска, поддаются идентификации и оценке. Большинство научных подходов по оценке риска объединяет методология актуарных расчетов, которая базируется на теории вероятности, актуальной статистике и долгосрочных прогнозах [Куклин, 2017].

На практике алгоритм оценки любыми рисками состоит из трех этапов: сбор информации, расчет средних величин, оценка отклонений. В последнее время одним из наиболее популярных методов управления риском является метод стресс-тестирования.

Стресс-тестирование представляет «систему методов оценки воздействия на состояние субъекта неблагоприятных событий, определяемых как «исключительные, но правдоподобные (возможные)» (exceptional but plausible) [Паздникова и др., 2014]. Идея метода - оценить ряд показателей, одним из которых является Value at Risk (далее - VaR) или «стоимость под риском». VaR одновременно выступает инструментом измерения возможных потерь в нормальных условиях функционирования рынка и механизмом оценки сто-

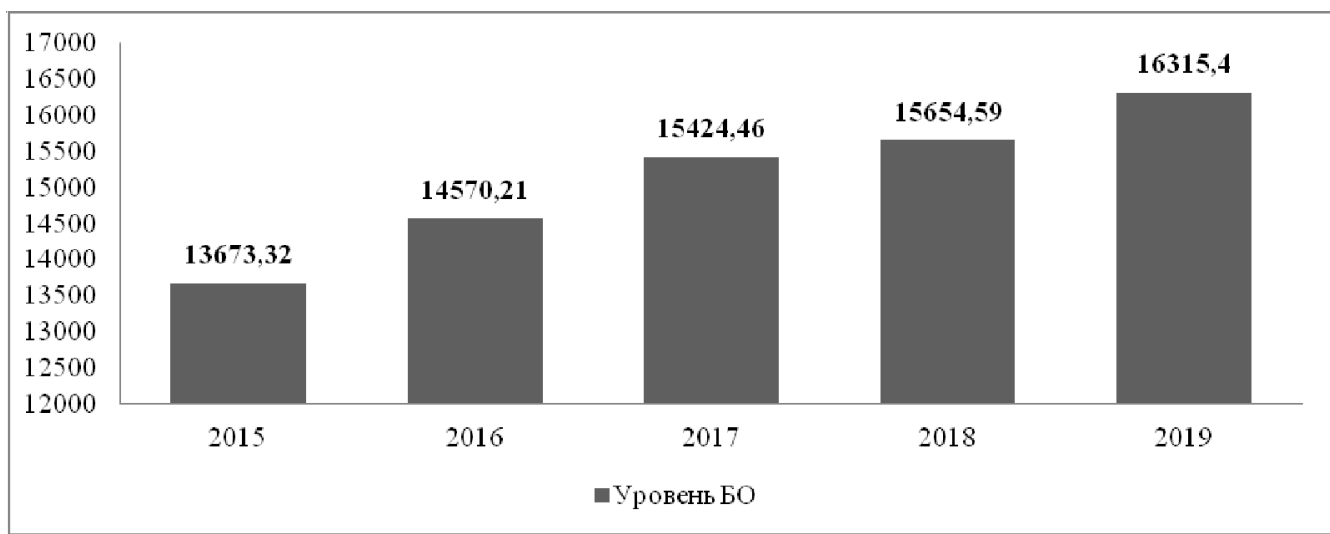

Рис. 3. Уровень бюджетной обеспеченности в Пермском крае 2015-2019 гг., руб. / чел. 2018].

Примечание. Составлено авторами по [Пермский край в цифрах ..., 2019; Пермский край в цифрах ..., 
Н.П. Паздникова, А.Ю. Важенина. Пенсионное обеспечение граждан Российской Федерации

имости резерва для покрытия убытков в результате возникновения негативной ситуации.

Апробируем VaR для оценки социального риска пенсионного обеспечения граждан, учитывая расчет стоимости необходимого резерва для покрытия убытков в случае невыполнения пенсионным фондом денежных выплат.

В качестве вероятностных показателей обозначим размер расходов по основным направлениям расходования бюджетных средств ОПФР по Пермскому краю, а именно расходы на выплату пенсий, предоставление материнского семейного капитала (мск) и социальные выплаты на детей (табл. 3).

Первоначально, рассчитаем показатель VaR по формуле [Паздникова и др., 2014]:

$$
\mathrm{VaR}=k \times x,
$$

где $k$ - коэффициент, соответствующий одному из доверительных интервалов; $x$ - стандартное отклонение.

Коэффициент согласно доверительному интервалу 95 \% по методологии Risk Metrics равен 1,645 .

Формула расчета стандартного отклонения по выборке рассчитывается как [Паздникова и др., 2014]:

$$
\partial=\sqrt{\frac{\sum\left(x_{i}-\overline{\mathrm{x}}\right)^{2}}{n}}
$$

где $x_{i}$ - платежи мск $-1068,085 ; x$ - пенсионные выплаты - 9318,$237 ; n$ - социальные выплаты 304,304 .
Следовательно:

VaR мск $=1,645 \times 1$ 068,085 = 1 756,999 млн руб.

VaR пенсии $=1,645$ × 9318,237 = 15 328,499 млн руб.

VaR социальные выплаты = 1,645 × 304,304= $=500,580$ млн руб.

По результатам полученных расчетов, резерв, необходимый для покрытия убытков в случае невыполнения ОПФР по Пермскому краю денежных выплат на предоставление материнского семейного капитала, составит 1 756,999 млн руб., пенсионного обеспечения 15 328,499 млн руб., социальных выплат 500,580 млн рублей. Более крупные расходы в течение анализируемого периода могут случиться только с пятипроцентной вероятностью. При неблагоприятном стечении обстоятельств в 95 \% случаев этот порог преодолен не будет.

\section{Заключение}

Таким образом, при увеличении уровня возможного риска по методу стресс-тестирования, можно оценить риск с учетом тех потерь, которые произойдут с определенной долей вероятности за определенный промежуток времени. Следует отметить, что бюджет Пенсионного фонда Российской Федерации и его Отделений находятся далеко не в критичном состоянии и имеет все перспективы для реализации основных задач, стоящих сегодня перед госу-

Таблица 3

Динамика и структура расходов бюджета ОПФР по Пермскому краю

\begin{tabular}{|c|c|c|c|c|c|c|c|c|c|c|}
\hline \multirow{2}{*}{ Виды расходов } & \multicolumn{2}{|c|}{$\begin{array}{c}\text { По состоянию } \\
\text { на } 01.01 .2016 \\
\end{array}$} & \multicolumn{2}{|c|}{$\begin{array}{c}\text { По состоянию } \\
\text { на 01.01.2017 } \\
\end{array}$} & \multicolumn{2}{|c|}{$\begin{array}{c}\text { По состоянию } \\
\text { на 01.01.2018 } \\
\end{array}$} & \multicolumn{2}{|c|}{$\begin{array}{c}\text { По состоянию } \\
\text { на 01.01.2019 } \\
\end{array}$} & \multicolumn{2}{|c|}{$\begin{array}{c}\text { По состоянию } \\
\text { на 01.01.2020 } \\
\end{array}$} \\
\hline & $\begin{array}{l}\text { Сумма, } \\
\text { млн руб. }\end{array}$ & $\begin{array}{c}\text { Доля, } \\
\%\end{array}$ & $\begin{array}{c}\text { Сумма, } \\
\text { млн руб. }\end{array}$ & $\begin{array}{c}\text { Доля, } \\
\%\end{array}$ & $\begin{array}{c}\text { Сумма, } \\
\text { млн руб. }\end{array}$ & $\begin{array}{c}\text { Доля, } \\
\%\end{array}$ & $\begin{array}{c}\text { Сумма, } \\
\text { млн руб. }\end{array}$ & $\begin{array}{c}\text { Доля, } \\
\%\end{array}$ & $\begin{array}{c}\text { Сумма, } \\
\text { млн руб. }\end{array}$ & $\begin{array}{c}\text { Доля, } \\
\%\end{array}$ \\
\hline Всего & 128469,5 & 100,0 & 137921,6 & 100,0 & 146776,9 & 100,0 & 147779,4 & 100,0 & 153845,4 & 100,0 \\
\hline МСK & 8122,0 & 6,3 & 8862,9 & 6,4 & 7484,4 & 5,1 & 6706,4 & 4,5 & 5801,7 & 3,8 \\
\hline Пенсии & 112161,8 & 87,3 & 120431,7 & 87,3 & 130225,7 & 88,7 & 131988,2 & 89,3 & 138662,5 & 90,1 \\
\hline $\begin{array}{l}\text { Социальные } \\
\text { выплаты }\end{array}$ & 7859,4 & 6,1 & 8180,0 & 5,9 & 8386,3 & 5,7 & 8448,8 & 5,7 & 8779,3 & 5,7 \\
\hline $\begin{array}{l}\text { Пенсионные } \\
\text { накопления }\end{array}$ & 321,7 & 0,3 & 443,3 & 0,3 & 676,4 & 0,5 & 552,9 & 0,4 & 506,6 & 0,3 \\
\hline Прочее & 4,7 & 0,001 & 3,7 & 0,001 & 4,1 & 0,001 & 83,1 & 0,1 & 95,3 & 0,1 \\
\hline
\end{tabular}
за 2015-2019 гг., млн руб. (без расходов на содержание аппарата Отделения) писки ...].

Примечание. Составлено авторами по: [Информационно-аналитическая система «Пояснительные за- 
дарством в части пенсионного обеспечения, гарантий устойчивой и финансово стабильной пенсионной системы на долгие годы вперед.

\section{СПИСОК ЛИТЕРАТУРЫ}

Амелин, Р. В. Государственные и муниципальные информационные системы в российском информационном праве: теоретико-правовой анализ / Р. В. Амелин ; под ред. С. Е. Чаннова. - М. : Гросс-Медиа, 2018. - 320 с.

Атанесян, Л. Р. Структура доходов и расходов бюджета Пенсионного фонда РФ / Л. Р. Атанесян // Цифровая наука. - 2020. - № 1. - С. 11-16.

Дмитриев, А. В. Государственное управление региональным социально-экономическим развитием посредством применения программно-целевых методов / А. В. Дмитриев // Стратегия устойчивого развития регионов России. -2013 . - № 14. - С. 60-63.

Жукова, Е. О. Подход к трактовке рисков системы пенсионного страхования / Е. О. Жукова // Аудит и финансовый анализ. - 2015. - № 1. C. $374-379$.

Куклин, А. А. От теории к практике актуарного оценивания пенсионных рисков России / А. А. Куклин, С. Е. Шипицына // Экономика региона. 2017. - Т. 13, вып. 3. -С. 716-731.

Паздникова, Н. П. Стресс-тестирование в управлении бюджетными рисками региона / Н. П. Паздникова, С. Е. Шипицына // Экономика региона. - 2014. - № 3. - С. 208-217.

Информационно-аналитическая система «Пояснительные записки к бухгалтерской (финансовой) отчетности Государственного учреждения - Отделения Пенсионного фонда Российской Федерации по Пермскому краю за 2015 2019 годы». - Электрон. текстовые дан. - Режим доступа: https://pfr.gov.ru (дата обращения: 12.01.2021). - Загл. с экрана.

Информационно-аналитическая система Федерального казначейства. - Электрон. текстовые дан. - Режим доступа: http://казначейство.pф/ gis/informacionno-analiticheskie-sistemyfederalnogo-kaznachejstva (дата обращения: 14.12.2020). - Загл. с экрана.

Конвенция Международной организации труда «О минимальных нормах социального обеспечения» (заключена в г. Женеве 28.06.1952). Электрон. текстовые дан. - Режим доступа: http://www.consultant.ru/document/cons_doc LAW_347616 (дата обращения: 01.02.2021).Загл. с экрана.

Кубарь, М. А. Теоретический обзор взглядов отечественных и зарубежных ученых на понятие «риск» / М. А. Кубарь, Н. Н. Дадыка // Электронный научно-методический журнал Омского ГАУ. - 2016. - № 4 (7). - Электрон. текстовые дан. - Режим доступа: https://elibrary.ru/ item.asp?id=27664354 (дата обращения: 23.01.2021). - Загл. с экрана.

Пермский край в цифрах. 2018 : крат. стат. сб. - Электрон. текстовые дан. - Режим доступа: https:// permstat.gks.ru (дата обращения: 12.02.2021).Загл. с экрана.

Пермский край в цифрах. 2019 : крат. стат. сб. - Электрон. текстовые дан. - Режим доступа: https:// permstat.gks.ru (дата обращения: 12.02.2021). Загл. с экрана.

\section{REFERENCES}

Amelin R.V., Channov S.E., ed. Gosudarstvennyye i munitsipal'nyye informatsionnyye sistemy $v$ rossiyskom informatsionnom prave: teoretikopravovoy analiz [State and Municipal Information Systems in Russian Information Law: Theoretical and Legal Analysis]. Moscow, Gross-Media Publ., 2018. 320 p.

Atanesyan L.R. Struktura dohodov $i$ rashodov bjudzheta Pensionnogo fonda RF [Structure of Income and Expenditure of the Budget of the Pension Fund of the Russian Federation]. Cifrovaja nauka, 2020, no.1, pp.11-16.

Dmitriev A.V. Gosudarstvennoe upravlenie regional'nym social'no-jekonomicheskim razvitiem posredstvom primenenija programmno-celevyh metodov [State Management of Regional Socio-Economic Development Through Program-Targeted Methods]. Strategija ustojchivogo razvitija regionov Rossii, 2013, no. 14, pp. 60-63.

Zhukova E.O. Podhod k traktovke riskov sistemy pensionnogo strahovanija [Approach to the Interpretation of the Pension Insurance System Risks]. Audit i finansovyj analiz [Audit and Financial Analysis], 2015, no. 1, pp. 374-379.

Kuklin A.A., Shipitsyna, S.E. Ot teorii k praktike aktuarnogo ocenivanija pensionnyh riskov Rossii [Actuarial Evaluation of Pension Risks of Russia: From Theory to Practice]. Jekonomika regiona [Economy of Region], 2017, vol. 13, iss. 3, pp. 716-731.

Pazdnikova N.P., Shipitsyna, S.E. Stress-testirovanie $v$ upravlenii bjudzhetnymi riskami regiona [Stress Analysis in Managing the Region's Budget Risks]. Jekonomika regiona [Economy of Region], 2014, no. 3, pp. 208-217.

Informacionno-analiticheskaja sistema «Pojas nitelnye zapiski $k$ buhgalterskoj (finansovoj) 
otchetnosti Gosudarstvennogo uchrezhdenija - Otdelenija Pensionnogo fonda Rossijskoj Federacii po Permskomu kraju za 2015-2019 gody» [Information and Analytical System "Explanatory Notes to the Accounting (Financial) Statements of the State Institution Branch of the Pension Fund of the Russian Federation in Perm Krai for 2015-2019']. URL: https://pfr.gov.ru (accessed 12 January 2021).

Informacionno-analiticheskaja sistema Federal'nogo kaznachejstva. [Information and Analytical System of the Federal Treasury]. URL: http:// казначейство.pф/gis/informacionnoanaliticheskie-sistemy-federalnogokaznachejstva (accessed 14 December 2020).

Konvencija Mezhdunarodnoj organizacii truda «O minimalnyh normah social'nogo obespechenija» (zakljuchena $v$ g. Zheneve 28.06.1952). [Convention No. 102 "On Minimum Standards of Social Security"
(Adopted in Geneva on June 28, 1952)]. URL: http://www.consultant.ru/document/cons_doc_ LAW_347616 (accessed 1 February 2021).

Kubar, M.A.A., Dadyka, N.N. Teoreticheskij obzor vzgljadov otechestvennyh i zarubezhnyh uchenyh na ponjatie «risk» [Theoretical Overview of the Views of Domestic and Foreign Scholars on the Concept of "Risk"]. Jelektronnyj nauchno-metodicheskij zhurnal Omskogo GAU [Research and Scientific Electronic Journal of Omsk SAU], 2016, no. 4 (7). URL: https:// elibrary.ru/item.asp?id=27664354 (accessed 23 January 2021).

Permskiy krayv tsifrakh. 2018 : krat. stat. sb. ["Perm Krai in Figures". 2018. Brief Statistical Collection]. URL: https://permstat.gks.ru (accessed 12 February 2021).

Permskiy kray v tsifrakh. 2019 : krat. stat. sb. ["Perm Krai in Figures". 2019. Brief Statistical Collection]. URL: https://permstat.gks.ru(accessed 12 February2021).

\section{Information About the Authors}

Natalya P. Pazdnikova, Doctor of Sciences (Economics), Professor, Department of Government and History, Perm National Research Polytechnic University, Prosp. Komsomolsky, 29, 614990 Perm, Russian Federation; Professor, Department of Entrepreneurship and Economic Security, Perm State National Research University, Bukireva St, 15, 614990 Perm, Russian Federation, pazdnikovan@mail.ru, https://orcid.org/0000-0002-0624-7894

Alena Yu. Vazhenina, Master Student, Department of Entrepreneurship and Economic Security, Perm State National Research University, Bukireva St, 15, 614990 Perm, RussianFederation, vazh-alena@yandex.ru, https://orcid.org/0000-0002-3189-4436

\section{Информация об авторах}

Наталья Павловна Паздникова, доктор экономических наук, профессор кафедры государственного управления и истории, Пермский национальный исследовательский политехнический университет, просп. Комсомольский, 29, 614990 г. Пермь, Российская Федерация; профессор кафедры предпринимательства и экономической безопасности, Пермский государственный национальный исследовательский университет, ул. Букирева, 15, 614990 г. Пермь, Российская Федерация, pazdnikovan@mail.ru, https://orcid.org/0000-0002-0624-7894

Алена Юрьевна Важенина, магистрант кафедры предпринимательства и экономической безопасности, Пермский государственный национальный исследовательский университет, ул. Букирева, 15, 614990 г. Пермь, Российская Федерация, vazh-alena@yandex.ru, https:/ /orcid.org/0000-0002-3189-4436 